\title{
SOCIALIZAÇÃO POLÍTICA E POLITIZAÇÃO ENTRE FAMÍLIAS DO MOVIMENTO DOS TRABALHADORES SEM TETO*
}

\author{
KIMI TOMIZAKI ${ }^{1}$ \\ Hamilton Harley de Carvalho-Silva ${ }^{1}$ \\ Maria Gilvania Valdivino Silva ${ }^{1}$
}

\begin{abstract}
RESUMO: Este artigo analisa os processos de socialização política e politização vivenciados por famílias engajadas no MTST com ênfase sobre o papel da família na aquisição de valores; a ressignificação de valores e atitudes em função de determinadas experiências individuais e/ou conjunturas econômicas e políticas, e os processos de ressocialização vivenciados no engajamento político. Os dados foram coletados por meio de entrevistas de caráter biográfico, observaçóes e conversas informais, e indicam que os entrevistados realizaram, ao longo de suas trajetórias, "negociaçóes" e "acomodaçóes" entre os valores familiares e aqueles adquiridos na militância, o que resulta em um quadro que integra valores das classes populares e alguns princípios do ideário socialista.
\end{abstract}

Palavras-chave: Socialização. Socialização política. Politização. Classes populares. Movimento dos Trabalhadores sem Teto.

\section{POLITICAL SOCIALIZATION AND POLITICIZATION BETWEEN FAMILIES OF THE HOMELESS WORKERS MOVEMENT (MTST)}

ABSTRACT: This paper analyzes the political processes of socialization and politicization experienced by families engaged in MTST (Homeless Workers Movement, in English) with emphasis on the family's role in the acquisition of values; the re-signification of values and attitudes according to certain individual experiences and/or economic and political circumstances; the re-socialization processes experienced in political engagement. The data were collected through biographical interviews, observations and informal conversations, and indicate that the respondents held over their careers

\footnotetext{
${ }^{*} \mathrm{O}$ artigo se baseia em dados coletados na pesquisa de doutoramento de Hamilton H. de Carvalho-Silva, intitulada Educação e práticas políticas entre mulheres militantes: o caso do MTST (CAPES), sob orientação da Prof. ${ }^{a}$ Kimi Tomizaki, e no âmbito do projeto de extensão "A dimensão educativa da luta pela moradia", coordenado pela Prof. ${ }^{a}$ Kimi Tomizaki e sediado no Condomínio João Cândido/Taboão da Serra/SP (financiamento Pró-reitorias de Extensão e Graduação da USP). ${ }^{1}$ Universidade de São Paulo, Faculdade de Educação - São Paulo (SP), Brasil. E-mails: kimi@usp.br, hamiltonharley@usp.br, maria.gilvania@usp.br DOI: 10.1590/ES0101-73302016166488
} 
"negotiations" and "accommodations" between family values and those values acquired in militancy, which results in a framework that integrates values of the popular classes and some principles of socialist ideology.

Keywords: Socialization. Political socialization. Politicization. Popular classes. Movimento dos Trabalhadores sem Teto.

\section{SOCIALISATION POLITIQUE ET POLITISATION PARMI LES FAMILLES DU MOUVEMENT DES SANS- TOIT (MTST)}

RESUMÉ: Cet article analyse les processus de socialisation politique et de politisation subis par des familles engagées dans MTST, en mettant l'accent sur le rôle de la famille dans l'acquisition de valeurs; la redéfinition de valeurs et d'attitudes en fonction de certaines expériences individuelles et/ou des circonstances économiques et politiques; et les processus de resocialisation expérimentés dans l'engagement politique. Les données ont été collectées à travers d'entretiens biographiques, d'observations et de conversations informelles et indiquent que les interrogées ont accompli au cours de leurs trajectoires des "négociations» et "adaptations» entre les valeurs de la famille et celles acquises dans le militantisme, en résultant un cadre qui intègre des valeurs des classes populaires avec certains principes de l'idéologie socialiste.

Mots-clés: Socialisation. Socialisation politique. Politisation. Classes populaires. Mouvement des sans-toit.

\section{Introdução}

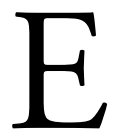

ste artigo tem como objetivo principal analisar determinados aspectos dos processos de socialização política e politização vivenciados por famílias moradoras do condomínio João Cândido, em Taboão da Serra, região metropolitana de São Paulo. Trata-se de um conjunto habitacional popular (192 apartamentos e, aproximadamente, 700 moradores), resultado de quase uma década de luta organizada pelo Movimento dos Trabalhadores Sem-Teto (MTST), nesse caso, em parceria com o Movimento dos Trabalhadores Sem-Terra (MST), construído com recursos do programa Minha casa, minha vida. Neste artigo, interessa-nos discutir: o papel da família na aquisição de valores e atitudes; a ressignificação destes diante de acontecimentos de ordem individual ou conjunturas econômicas e políticas; e a "ressocialização" vivenciada pelos indivíduos por meio da participação no MTST. Os dados que serão apresentados foram coletados no quadro de uma pesquisa sobre o engajamento de mulheres na luta por moradia e de um projeto de extensão universitária, ambos em curso. Ao longo de onze meses (durante as atividades do projeto de extensão, assim como em manifestações 
de rua, assembleias e reunióes na sede do MTST), realizamos oito entrevistas e observaçôes no próprio condomínio, além de observação participante em duas ocupaçôes de terreno.

O MTST, que surgiu nos anos $1990^{1}$, reconhece-se como um movimento de trabalhadores urbanos que, para além da moradia, luta também por transformaçóes sociais mais radicais, tendo em vista combater a miséria nos centros urbanos, formando militantes e avançando rumo à construção do socialismo (MTST, 2013). Nos últimos dez anos, as ações do MTST tiveram repercussão nacional e internacional: sua inegável projeção pública em volumosas manifestaçóes de rua, ocupaçôes de terrenos ociosos/ irregulares e bloqueios de estradas e rodovias, ganhou destaque na mídia e protagonismo no campo da esquerda brasileira. Atualmente, segundo estimativas do próprio movimento, 50 mil famílias vivem em algum tipo de ocupação ou estão organizadas em núcleos.

Pelos dados coletados junto às famílias do condomínio, podemos afirmar que os oito entrevistados representam o perfil majoritário dos moradores do João Cândido: trabalhadores e trabalhadoras migrantes, de origem rural; com baixa escolaridade; inseridos no mercado informal de trabalho ou no setor de serviços, em postos que não exigem qualificação profissional específica; cujos filhos, em geral, estão matriculados na escola, embora não sejam incomuns casos de fracasso e abandono escolar. A condição social do grupo fica mais clara quando a comparamos com alguns indicativos da populaçáo brasileira: enquanto a escolaridade média dos indivíduos com mais de 25 anos de idade atingiu o patamar de 7,7 anos de estudo, os entrevistados têm em média 3,5 anos de escolaridade; em relação às taxas de natalidade, enquanto as mulheres brasileiras têm em média 1,9 filho, entre as entrevistadas a média é de 5,3 filhos (IBGE, 2010).

Segundo os depoentes, suas famílias de origem viviam em precárias condiçóes financeiras, muitas vezes agravadas pelo abandono ou morte do pai. Em geral, a migração para zonas urbanas em busca de melhores condições de vida e trabalho contou com o suporte de algum parente ou amigo já instalado na periferia de São Paulo. A "vida na cidade" foi marcada pela precariedade típica da inserção no mercado informal de trabalho e pelo alto custo da moradia, em função da especulaçáo imobiliária, o que obrigou essas famílias a se distanciarem das regióes mais centrais.

Em geral, a aproximaçáo dos entrevistados com o MTST se deu por meio do convite de algum familiar ou vizinho já engajado ou pelo contato direto com uma ocupação de terreno ocorrida nas proximidades de suas residências. De acordo com nossas observaçóes e entrevistas, a adesão ao movimento exige a frequência e participação em diferentes tipos de atividades, tais como assembleias, manifestaçóes públicas e ocupaçôes de terrenos. Quando se toma parte em uma ocupação, o participante torna-se um "acampado" até o momento da desocupação do terreno, o que geralmente ocorre por ordem judicial. As ocupaçôes têm longevidade variada e 
podem ser encerradas também com ganhos desiguais (da conquista de um terreno até táo somente a concessão de algumas "bolsas-aluguel"2); a partir do momento em que uma ocupaçáo é finalizada, seus participantes se organizam em núcleos. Toda forma de participação é revertida em uma escala de pontuação organizada em listas de presença, que hierarquizam os militantes por "densidade de atuação", o que definirá quais participantes acessarão mais rapidamente suas casas ou apartamentos (salvo em alguns casos considerados preferenciais, como aqueles que envolvem idosos e enfermos). Portanto, os moradores do condomínio estão entre aqueles que tiveram maior participação em seu núcleo, ao longo de quase uma década de luta pela moradia, o que indica forte traço de resiliência.

\section{Socialização política, politização e classes populares}

Retomando a clássica formulação de Berger \& Berger (1975), socializaçâo é o processo por meio do qual nos tornamos membros de uma sociedade, o que pressupóe transmissão e assimilação de determinados conhecimentos, valores, práticas, comportamentos, quadros de percepção e avaliação do mundo e de nós mesmos. E, embora a infância seja apontada como um período privilegiado para a formação de disposiçóes duráveis, as múltiplas socializaçóes secundárias, que se estendem ao longo da vida, são capazes de reconfigurar valores e comportamentos adquiridos no seio familiar (BOURDIEU, 2009; BOURDIEU \& WACQUANT, 1992; BERGER \& LUCKMANN, 2004; BERGER \& BERGER, 1975; DUBAR, 2005; PERCHERON, 1993; TOMIZAKI, 2010).

A socialização política, por sua vez, é uma das dimensões do processo de socialização, e diz respeito especificamente à transmissão e à aquisição de valores, condutas, percepçóes e preferências sobre política ${ }^{3}$. Sendo assim, podemos afirmar que todo indivíduo é socializado politicamente, embora as características e efeitos desse processo possam variar enormemente: em um plano micro, segundo a origem social, trajetória familiar, nível de instrução, ocupação ou profissão dos indivíduos; e em um plano macro, em função de determinadas conjunturas econômicas, sociais e políticas (BARGEL, 2009; CAETANO, 2013; DUBAR, 2005; PERCHERON, 1993; LAGROYE et al., 2006; MUXEL, 2001).

A expressão "socialização política" foi usada pela primeira vez em 1954, por Seymour Lipset, mas somente a partir da obra de Herner Hyman, Political Socialization (1959), essas pesquisas passaram a constituir uma área de investigação e enfatizar o papel determinante do ambiente familiar e dos valores assimilados na infância e adolescência para a formação de disposições sobre política, especialmente no que se refere à identificação partidária e à opção de voto. Pesquisas posteriores apontaram que outras instâncias de socialização (como a escola, o grupo de pares e o ambiente profissional) são também decisivas na identificação política dos indivíduos. Não se trata, portanto, de 
negar que os indivíduos tenham sua relação com a política influenciada pelos valores e princípios familiares. No entanto, para compreender os processos de socialização política é necessário verificar o peso tanto dos efeitos da transmissão intergeracional quanto dos acontecimentos políticos ${ }^{4}$ (SCHMIDT, 2000; PERCHERON, 1987; 1993; MUXEL \& PERCHERON, 1985; OPPO, 2009; DARMON, 2010; IHL, 2002; MUXEL, 1997; 2001; GAXIE, 2002).

Se a socialização política, como uma dimensão dos processos gerais de socialização, perpassa toda a sociedade, a politização, por sua vez, trata-se de um processo mais específico, que Lagroye define como uma operação social, que não pode ser imputada somente a estratégias, atores e organizaçóes políticas. Assim, a politização abarca também uma dimensão individual, que se funda em preocupaçóes muito concretas, ambiçóes ordinárias e finalidades sociais legítimas, cuja convergência perturba a ordem hierárquica dos "lugares” sociais (LAGROYE, 2003). Dada a amplitude dessa noção, acreditamos ser fundamental que as pesquisas que assumam tal fenômeno como objeto respondam algumas questóes fundamentais que tornam o debate inteligível: a partir de qual momento poderíamos dizer que existe um processo de politização e que estamos diante de indivíduos politizados? $\mathrm{O}$ que permite ou possibilita a politização dos indivíduos ou quais são os vetores de politização, que podem variar não somente em função dos grupos estudados, mas também em função dos indicadores assumidos pelos pesquisadores?

Para o caso que será aqui estudado, interessa-nos, sobretudo, os autores para quem, no âmbito de sociedades democráticas, a passagem de uma perspectiva individualista à uma perspectiva coletiva já pode ser considerada um importante indicador de politização - entendida neste texto como um processo que resulta na formação de indivíduos e grupos que, com diferentes níveis de compreensão e envolvimento, estão interessados pela política como causa e solução para os problemas de ordem social, desenvolvendo disposiçóes para a luta coletiva na defesa de direitos também coletivos. Os vetores de politização podem ser múltiplos e, no caso de homens e mulheres participantes ou militantes do MTST, percebemos que há um grande peso de suas precárias condiçóes de vida e trabalho. Assim, a impossibilidade de acessar direitos mínimos e o sentimento de insegurança, instabilidade social e econômica é o vetor fundamental de politização para esse grupo, o que ganha outro sentido no "encontro" com o MTST, quando a angústia individual se desdobra em indignação e, ao mesmo tempo, em sentimento de pertencimento a uma forte e coesa rede de proteção, uma "nova família" (DUCHESNE \& HAEGEL, 2004; AÏT-AOUDIA et al., 2011; TOMIZAKI, 2009).

\section{As famílias do João Cândido: classes populares e participação política}

A análise dos processos de socialização política e politização vivenciados pelas famílias do condomínio João Cândido exigiu a compreensão do "lugar" 
ocupado por esse grupo, o que nos remeteu ao debate sobre "classes populares". Diante da complexidade dessa definição, aqui o conceito de classes populares designará grupos sociais caracterizados por uma posição dominada no espaço social em diferentes dimensôes (econômica, cultural, simbólica e política), que compartilham de um futuro provável similar e limitado, além de traços comuns em termos de cultura, modos de vida e representaçôes sociais (BERTONCELO, 2014; GUIMARÃES, 1999; COLLOVALD; SAWICKI, 1991; SCHWARTZ, 2011; SIBLOT et al., 2015).

No que tange à realidade brasileira, as pesquisas de Souza (2009; 2012) apontam para a necessidade de que a noção de classe social seja entendida para além de uma posição no sistema produtivo, mas sobretudo "como fonte de todas as heranças simbólicas, valorativas, morais e existenciais que se passam de pais para filhos por laços de afeto" (SOUZA, 2009, p. 45). O autor ainda explica que:

\begin{abstract}
Existe uma "luta de classes" intestina e inegável [no Brasil], que permite que toda uma classe que náo consegue, pelo abandono social e político, incorporar conhecimento útil para participar no mercado econômico competitivo, possa ser explorada como mão de obra barata - reduzida a dispêndio muscular pela ausência da incorporação de conhecimento valorizado pelo mercado competitivo - nas funções de empregada, faxineira, babá, zelador, prostituta, motoboy, porteiro, e todo tipo de trabalho, perigoso, sujo ou pesado, de modo a poupar tempo das classes média e alta para estudo e trabalho de funçóes prestigiosas e rentáveis. [...] Quando esta classe chega ao noticiário é quase sempre pela oposição bandido-polícia, despolitizando os conflitos sociais e criando estigmas contra os mais fracos (SOUZA, 2011, p. 38).
\end{abstract}

Em um primeiro momento, não seria exagero afirmar que, de acordo com a origem, trajetória e alguns aspectos da atual situação social, econômica e cultural dos moradores do condomínio Joáo Cândido (o que poderia também ser generalizável para o conjunto dos trabalhadores ligados ao MTST), trata-se do grupo identificado por Souza como a "ralé": "uma classe inteira de indivíduos, não só sem capital cultural nem econômico em qualquer medida significativa, mas desprovida, esse é o aspecto fundamental, das precondiçôes sociais, morais e culturais que permitem essa apropriação" (SOUZA, 2009, p. 21).

No entanto, a militância no MTST permitiu que, em alguns aspectos, esse grupo se deslocasse objetiva e subjetivamente dessa posição social, e isso não se deu somente pelo acesso à "casa própria", mas, sobretudo, pelos efeitos duráveis do engajamento político, que, por sua vez, não depende do pertencimento a uma classe social específica. A rigor, nenhuma propriedade social, seja ela qual for (pertencimento de classe, idade, sexo, renda, status profissional, escolarização), tem considerável capacidade explicativa sobre o 
fenômeno do engajamento, se náo for analisada em uma dada configuração, na qual ela se atualiza e contribui para a formação de disposiçóes à ação coletiva: "é na sucessão de encontros entre as propriedades sociais e os contextos variáveis de socialização que se formam as disposições" (FILLIEULE \& PUDAL, 2010, p. 173).

A compreensão do engajamento militante tem sido um tema de destaque nas últimas duas décadas, e os principais estudos apontam que sua análise exige uma perspectiva relacional, que considere as interações entre indivíduos e com contextos sociais e políticos, as trajetórias dos militantes e os sentidos atribuídos pelos indivíduos à sua trajetória e ao engajamento (SAWICKI; SIMÉANT, 2011; LECLERCQ, 2011; TOMIZAKI, 2013).

Como dito anteriormente, as propriedades sociais do conjunto dos entrevistados (Tabela 1), bem como suas experiências de militância no MTST, guardam entre si homologias que nos permitem recorrer à apresentaçáo de duas trajetórias que podem ser consideradas exemplares desse grupo e nos possibilitam reconstituir algumas etapas fundamentais dessas socializaçóes militantes.

\section{Ana: militância e religião}

Ana nasceu em 1959, em São Paulo, filha de um pedreiro e uma diarista, migrantes da Bahia e de Minas Gerais. A família sempre viveu em condições muito precárias, em uma ocupação irregular na periferia da Zona Sul. Seu pai os abandonou muito cedo, e sua mãe, analfabeta, enfrentava graves dificuldades para sustentar os sete filhos, o que fez com que Ana desistisse da escola aos 12 anos de idade para assumir precocemente os afazeres domésticos e o cuidado dos irmáos. Assim como outros entrevistados, Ana considera que recebeu uma educaçâo familiar rigorosa, pautada, sobretudo, na interdição de "ficar na rua", onde se encontra só "o que não presta", e na valorização do trabalho e da honestidade.

Minha mãe ensinou nós muito bonito. Nunca mexer nas coisas dos outros. (...) Os irmãos são tudo assim (...), tudo trabalhador. Tudo que a gente tem a gente mesmo que compra. Corre e vai atrás (...) e nunca cruza o braço. Tudo que você vai à luta você consegue. (...) [Meus filhos] ensinei trabalhar para conseguir o que você quer.

A vida de Ana não se tornou mais fácil após a formação de sua própria família: aos 21 anos, foi abandonada pelo marido, logo após o nascimento do seu primeiro filho. Em seguida, ela foi diagnosticada com uma grave doença ${ }^{5}$ e aposentada por invalidez. Como o valor da aposentadoria é muito baixo, ela precisou continuar trabalhando em diferentes ocupaçóes: operária, diarista e 
Tabela 1

Caracterização geral dos entrevistados.

\begin{tabular}{|c|c|c|c|c|}
\hline Nome Fictício & Ana & Léa & Neiva & Sandra \\
\hline $\begin{array}{l}\text { Ano de } \\
\text { nascimento }\end{array}$ & 1959 & 1982 & 1955 & 1979 \\
\hline UF de origem & São Paulo & Bahia & Espírito Santo & Sáo Paulo \\
\hline Ano de Migração & -- & 1988 & 1970 & - \\
\hline $\begin{array}{l}\text { Escolaridade do } \\
\text { Pai }\end{array}$ & Desconhecida & Desconhecida & $\begin{array}{l}1^{\text {a }} \text {. série do Ensino } \\
\text { Fundamental (EF) }\end{array}$ & Desconhecida \\
\hline Profissão do Pai & $\begin{array}{l}\text { Pedreiro/ } \\
\text { vidraceiro }\end{array}$ & Desconhecida & $\begin{array}{c}\text { Agricultor } \\
\text { (empregado) }\end{array}$ & Desconhecida \\
\hline $\begin{array}{l}\text { Escolaridade da } \\
\text { máe }\end{array}$ & Analfabeta & Analfabeta & Analfabeta & Analfabeta \\
\hline Profissão da mãe & Diarista & $\begin{array}{l}\text { Agricultora } \\
\text { (empregada) }\end{array}$ & $\begin{array}{l}\text { Agricultora } \\
\text { (empregada) }\end{array}$ & Doméstica \\
\hline $\begin{array}{l}\text { Número de } \\
\text { irmãos }\end{array}$ & 5 (cinco) & 4 (quatro) & 9 (nove) & 8 (oito) \\
\hline $\begin{array}{l}\text { Idade com } \\
\text { que começou } \\
\text { a trabalhar e } \\
\text { atividade }\end{array}$ & $\begin{array}{l}12 \text { anos } \\
\text { (cuidado dos } \\
\text { irmãos) }\end{array}$ & $\begin{array}{c}6 \text { anos } \\
(\text { serviços } \\
\text { domésticos, } \\
\text { ajudando a mãe) }\end{array}$ & $\begin{array}{l}10 \text { anos } \\
\text { (lavar roupa "pra } \\
\text { fora” e lavoura) }\end{array}$ & $\begin{array}{c}13 \text { anos } \\
\text { (doméstica) }\end{array}$ \\
\hline $\begin{array}{l}\text { Escolaridade do } \\
\text { entrevistado }\end{array}$ & $\begin{array}{c}\text { Ensino Médio } \\
\text { (Educação de Jovens } \\
\text { e Adultos - EJA) }\end{array}$ & $3^{a}$ série EF & $\begin{array}{l}\text { Ensino Médio } \\
\text { (EJA) }\end{array}$ & $3^{\mathrm{a}}$ série $\mathrm{EF}$ \\
\hline Estado civil & Separada & Solteira & Casada & Casada \\
\hline $\begin{array}{l}\text { Composição } \\
\text { familiar }\end{array}$ & Monoparental & Monoparental & Nuclear & Nuclear \\
\hline No de filhos & 2 (dois) & 5 (cinco) & 3 (três) & 7 (sete) \\
\hline Profissáo atual & Diarista/ cuidadora & Cozinheira & Dona de casa & Faxineira \\
\hline $\begin{array}{l}\text { Média salarial } \\
\text { atual }\end{array}$ & $1 \mathrm{SM}$ & $1,5 \mathrm{SM}$ & -- & $1 \mathrm{SM}$ \\
\hline $\begin{array}{l}\text { Condições } \\
\text { anteriores de } \\
\text { moradia }\end{array}$ & $\begin{array}{l}\text { Ocupação irregular } \\
\text { (pagando aluguel) }\end{array}$ & $\begin{array}{l}\text { Vivia de favores } \\
\text { (casa de amigos e } \\
\text { parentes) }\end{array}$ & $\begin{array}{l}\text { Pagava aluguel em } \\
\text { bairro periférico }\end{array}$ & $\begin{array}{c}\text { Ocupaçáo } \\
\text { irregular (pagando } \\
\text { aluguel) }\end{array}$ \\
\hline $\begin{array}{l}\text { Principal } \\
\text { motivação de } \\
\text { entrada no MTST }\end{array}$ & $\begin{array}{l}\text { Parar de pagar } \\
\text { aluguel }\end{array}$ & $\begin{array}{c}\text { Buscar uma } \\
\text { moradia (não } \\
\text { tinha onde morar) }\end{array}$ & $\begin{array}{l}\text { Parar de pagar } \\
\text { aluguel }\end{array}$ & $\begin{array}{l}\text { Parar de pagar } \\
\text { aluguel }\end{array}$ \\
\hline $\begin{array}{l}\text { Sentimento em } \\
\text { relação ao MTST }\end{array}$ & $\begin{array}{l}\text { Coletividade e } \\
\text { solidariedade }\end{array}$ & Uma nova família & $\begin{array}{l}\text { Coletividade e } \\
\text { solidariedade }\end{array}$ & $\begin{array}{l}\text { Coletividade e } \\
\text { solidariedade }\end{array}$ \\
\hline $\begin{array}{l}\text { Experiência de } \\
\text { liderança }\end{array}$ & $\begin{array}{c}\text { Coordenação de } \\
\text { núcleo }\end{array}$ & $\begin{array}{c}\text { Coordenação de } \\
\text { núcleo }\end{array}$ & $\begin{array}{l}\text { Coordenação de } \\
\text { núcleo }\end{array}$ & $\begin{array}{l}\text { Coordenação de } \\
\text { núcleo }\end{array}$ \\
\hline $\begin{array}{l}\text { Tipo de } \\
\text { continuidade da } \\
\text { militância após a } \\
\text { conquista da casa }\end{array}$ & $\begin{array}{l}\text { Participação em } \\
\text { atos, assembleias } \\
\text { e organizaçáo de } \\
\text { acampamentos }\end{array}$ & $\begin{array}{l}\text { Participação em } \\
\text { atos, assembleias } \\
\text { e organizaçáo de } \\
\text { acampamentos }\end{array}$ & $\begin{array}{l}\text { Participação em } \\
\text { atos e assembleias }\end{array}$ & $\begin{array}{l}\text { Participação em } \\
\text { atos e assembleias }\end{array}$ \\
\hline
\end{tabular}

\section{Continua...}


Tabela 1

Continuação.

\begin{tabular}{|c|c|c|c|c|}
\hline Nome Fictício & Inês & Irineu & Adriana & Ângelo \\
\hline $\begin{array}{l}\text { Ano de } \\
\text { nascimento }\end{array}$ & 1965 & 1959 & 1969 & 1963 \\
\hline UF de origem & Paraíba & Paraíba & Rio de Janeiro & Paraíba \\
\hline Ano de Migração & 2014 & 2004 & 1985 & 1982 \\
\hline $\begin{array}{l}\text { Escolaridade do } \\
\text { Pai }\end{array}$ & Desconhecida & Analfabeto & Analfabeto & Analfabeto \\
\hline Profissão do Pai & $\begin{array}{c}\text { Agricultor } \\
\text { (proprietário) }\end{array}$ & $\begin{array}{c}\text { Agricultor } \\
\text { (proprietário) }\end{array}$ & -- & $\begin{array}{c}\text { Agricultor } \\
\text { (proprietário) }\end{array}$ \\
\hline $\begin{array}{l}\text { Escolaridade da } \\
\text { máe }\end{array}$ & Analfabeta & Analfabeta & Analfabeta & Analfabeta \\
\hline Profissão da mãe & $\begin{array}{c}\text { Agricultora } \\
\text { (proprietária) }\end{array}$ & $\begin{array}{c}\text { Agricultora } \\
\text { (proprietária) }\end{array}$ & Doméstica & $\begin{array}{c}\text { Agricultora } \\
\text { (proprietária) }\end{array}$ \\
\hline $\begin{array}{l}\text { Número de } \\
\text { irmãos }\end{array}$ & 2 (dois) & 8 (oito) & 8 (oito) & 12 (doze) \\
\hline $\begin{array}{l}\text { Idade com que co- } \\
\text { meçou a trabalhar } \\
\text { e atividade }\end{array}$ & 10 anos (lavoura) & $\begin{array}{c}7 \text { anos } \\
\text { (lavoura) }\end{array}$ & $\begin{array}{c}8 \text { anos } \\
\text { (serviços domés- } \\
\text { ticos, ajudando a } \\
\text { mãe) }\end{array}$ & $\begin{array}{c}7 \text { anos } \\
\text { (lavoura) }\end{array}$ \\
\hline $\begin{array}{l}\text { Escolaridade do } \\
\text { entrevistado }\end{array}$ & $\begin{array}{c}3^{\mathrm{a}} \text { série } \mathrm{EF} \\
\text { (porém, não lê) }\end{array}$ & $8^{\mathrm{a}}$ série EF & $4^{a}$ série $\mathrm{EF}$ & $1^{a}$ série $\mathrm{EF}$ \\
\hline Estado civil & Casada & Casado & Casada & Casado \\
\hline $\begin{array}{l}\text { Composição } \\
\text { familiar }\end{array}$ & Nuclear & Nuclear & Nuclear & Nuclear \\
\hline No de filhos & $\begin{array}{c}13 \text { (treze), } \\
\text { sendo } 7 \text { vivos }\end{array}$ & 13 (treze) & 5 (cinco) & 5 (cinco) \\
\hline Profissão atual & Dona de casa & Desempregado & Dona de casa & Pintor \\
\hline $\begin{array}{l}\text { Média salarial } \\
\text { atual }\end{array}$ & -- & -- & -- & Variável \\
\hline $\begin{array}{l}\text { Condiçôes ante- } \\
\text { riores de moradia }\end{array}$ & $\begin{array}{c}\text { Vivia em um po- } \\
\text { voado no interior } \\
\text { da PB } \\
\end{array}$ & $\begin{array}{l}\text { Pagava aluguel em } \\
\text { bairro periférico }\end{array}$ & $\begin{array}{l}\text { Ocupação irregular } \\
\text { (sem aluguel) }\end{array}$ & $\begin{array}{l}\text { Ocupação irregular } \\
\text { (sem aluguel) }\end{array}$ \\
\hline $\begin{array}{l}\text { Principal } \\
\text { motivaçáo de } \\
\text { entrada no MTST }\end{array}$ & $\begin{array}{l}\text { Caso particular } \\
\text { (não participou } \\
\text { do movimento) }\end{array}$ & $\begin{array}{l}\text { Conquistar uma } \\
\text { moradia para } \\
\text { trazer a família } \\
\text { da PB }\end{array}$ & $\begin{array}{l}\text { Busca de uma } \\
\text { moradia digna }\end{array}$ & $\begin{array}{l}\text { Melhoria de condi- } \\
\text { çôes de moradia }\end{array}$ \\
\hline $\begin{array}{l}\text { Sentimento em } \\
\text { relaçáo ao MTST }\end{array}$ & Não declarado & $\begin{array}{l}\text { Coletividade e } \\
\text { solidariedade }\end{array}$ & $\begin{array}{l}\text { MTST mudou } \\
\text { sua vida }\end{array}$ & $\begin{array}{l}\text { Coletividade e } \\
\text { solidariedade }\end{array}$ \\
\hline $\begin{array}{l}\text { Experiência de } \\
\text { liderança }\end{array}$ & Nenhuma & $\begin{array}{l}\text { Coordenação de } \\
\text { núcleo }\end{array}$ & Nenhuma & Nenhuma \\
\hline $\begin{array}{l}\text { Tipo de continui- } \\
\text { dade da militância } \\
\text { após a conquista } \\
\text { da casa }\end{array}$ & Nenhuma & $\begin{array}{c}\text { Participaçáo em } \\
\text { atos, assembleias } \\
\text { e organização de } \\
\text { acampamentos }\end{array}$ & -- & $\begin{array}{l}\text { Participação em } \\
\text { algumas assem- } \\
\text { bleias }\end{array}$ \\
\hline
\end{tabular}

Fonte: elaboração própria (2016). 
cuidadora de idosos e enfermos "na casa das madames", evidentemente sem possibilidade de acessar direitos trabalhistas. Um segundo momento de grande dificuldade para Ana ocorreu no período de doença e morte do seu segundo marido, vítima de tuberculose. De acordo com seu depoimento, ela considera que a vida de sua família só não foi mais precária por conta de ter somente dois filhos, resultado de uma opçáo consciente e deliberada pelo controle de natalidade, que ela classifica como uma "atitude inteligente": "cuidava sozinha dos filhos, pagava aluguel num quarto e cozinha. Uma luta minha vida foi. Passei muita necessidade. (...) Ainda bem que tenho só dois filhos na vida. Não fui tâo burra assim! Tá vendo como minha cabeça é diferente?".

Ao longo de seu depoimento, Ana busca demarcar as evidências de que ela é diferente das outras mulheres em geral, sobretudo, em função do controle de natalidade e pela recusa de relacionamentos abusivos, o que deixa transparecer a percepção de que cabe à mulher protagonizar seu próprio destino, a tal ponto que, quando fala de si e de suas irmãs, o valor moral do trabalho aparece entrelaçado com a recusa em ser vítima de violência doméstica.

Deu certo, deu. Náo deu, eu caio fora. Sou daquele tipo de mulher que é tudo ou nada. Era um bom marido [referindo-se ao terceiro marido], não me deixava faltar nada, só que bebia. Se ponhasse a mão em mim, era cabo de panela, o que viesse. Uma vez me pegou no braço. Taquei uma garrafa nele. Apanhar não! Não sou essas mulher que apanha. As minhas irmãs é tudo igual a eu. Decidida, trabalhadeira!

De família católica, Ana se converteu à igreja evangélica há 16 anos, atualmente frequenta a Assembleia de Deus, na qual desempenha a função de "obreira": realiza abertura de cultos, limpa a igreja, visita "irmãos" doentes "que necessitam ouvir a palavra". Foi na igreja também que Ana reconfigurou os sentidos atribuídos à escolarização, sobretudo no que diz respeito às habilidades de leitura e de comunicação, pois como obreira precisa ler em voz alta e interpretar trechos da Bíblia.

A religião parece exercer considerável influência sobre os modos de percepção que Ana tem do mundo, de si e de sua trajetória. No entanto, é possível perceber que a adesão aos princípios religiosos é nuançada com a necessidade de conviver em ambientes e com pessoas de diferentes religiōes ou não religiosas: "eu sei separar religião, movimento, amizade e familia. É tudo assim separadinho". Vale dizer que a igreja frequentada por Ana não se opóe à sua militância, inclusive lhe dando a oportunidade de testemunhar publicamente suas conquistas no MTST, no qual está engajada desde 2005.

Mudou toda a minha vida. (...) Tinha que cuidar da minha mãe, da igreja, da neta... Tinha que ir pro movimento. (...) Perdi ser- 
viço bom. Trabalhava em casa de família, dava uma limpadinha, fazia o almoço e tinha que ir pro movimento. Eu ficava doida. (...) Perdi o serviço, ainda bem que eu era aposentada já. Comecei a vender pano de prato, revista. Eu corria atrás, ajudava a inteirar o dinheiro pra pagar o aluguel. Eu já sofri... Agora não, eu estou na paz de Deus. (...) Tenho muito amor por esse movimento. (...) Vou nos terrenos [ocupaçóes] até hoje. Quando tem ocupação, eu vou. Mesmo estando morando aqui, eu nunca deixo de ir. (...) Ah, uma pessoa que eu gosto muito é o Guilherme [Boulos]! ' Se não fosse o Guilherme... (...) Primeiramente Deus, nós, o movimento, e o Guilherme. Se o Guilherme não tiver num lugar, pra mim não existe reuniáo, não existe movimento, não existe nada pra mim. (...) Militância ninguém sabe nem chegar no pé do Guilherme, nem na unhinha. (...) Eu oro muito pro Guilherme.

Atualmente, Ana faz "bicos” como cuidadora de idosos e se ocupa da mãe, também idosa e doente. Além disso, planeja concluir o ensino médio e fazer curso de auxiliar de enfermagem. Sua filha mais jovem (27 anos, auxiliar de cozinha, casada e máe de uma menina de 5 anos) concluiu o ensino médio e aspira ingressar no ensino superior. O filho mais velho (36 anos, pintor) estudou até o quarto ano do ensino fundamental.

\section{Léa: "renascimento" pela militância}

Léa nasceu em 1982, na cidade de Nova Canaã (BA); sua mãe, uma trabalhadora rural analfabeta, criou cinco filhos sem ajuda do marido, que os abandonou. Em 1988, a família de Léa se mudou para a periferia da Zona Sul de São Paulo, a convite de um tio materno, que lhes ofereceu "um cômodo e banheiro" nos fundos de sua casa. Somente nesse período ela frequentou a escola, até a terceira série. Os dois irmãos mais velhos se empregaram rapidamente e passaram a viver nas casas dos patróes. Sua mãe era alcoolista, o que resultava em frequentes conflitos familiares, até que seu tio os expulsou de casa. Então, Léa, sua mãe e seu irmão mais novo ocuparam o vestiário de um campo de futebol abandonado no bairro do Butantã: "me lembro como hoje, minha mãe capinou, arrumou tudo $e$ falou pra gente 'nós agora vamos morar aqui'”. Não havia energia elétrica, nem água encanada. O pouco que tinham vinha da ajuda de famílias da vizinhança. Sua mãe lavava roupas em "casas de família” e perambulava "de bar em bar", deixando os filhos sozinhos por longos períodos. Quando Léa tinha aproximadamente 10 anos, sua mãe foi atropelada e faleceu.

Sem rede de apoio familiar, Léa e o irmão continuaram a morar no vestiário até seus 14 anos de idade. Nesse período, recebiam a ajuda de vizinhos, recolhiam restos de alimentos nas feiras livres e trabalhavam informalmente: seu 
irmão vendendo caldo de cana e Léa passando roupa nas casas da vizinhança. Vítima de diferentes abusos e assédio, Léa ficou grávida ainda aos 14 anos; seus dois primeiros filhos foram encaminhados para adoção pelo "juizado de menores". Dos 15 aos 18 anos de idade, ela morou em abrigos para meninas, nos quais a experiência foi particularmente difícil, visto que a adolescente não conseguia se adequar às rígidas regras dos locais. Considerada insubordinada, era constantemente repreendida e castigada.

Aos 21 anos, Léa passou a morar com sua irmã mais velha, com quem tinha vários conflitos. Com o nascimento de seu quarto filho, todos de diferentes pais, Léa considerava que "já tinha juizo, já tinha me tornado mulher. Eu tava mais madura, trabalhando, planejando as coisas...”. Trabalhava, então, como faxineira e, com a ajuda da irmã, conseguia cuidar dos dois filhos menores. No entanto, o anúncio da quinta gravidez resultou em sua expulsão da casa da irmã e na perda do emprego.

Grávida, com dois filhos, desempregada, sem ter onde morar, Léa foi aconselhada por uma antiga vizinha a participar do MTST, em Taboão da Serra. Já na primeira visita à ocupaçâo, Léa viu a possibilidade de se abrigar com seus filhos:

Cheguei no acampamento com minhas coisas e meus filhos e fiz meu barraco. Dormia no cháo com um tapete. Depois, fiz uma cama com uns paus lá. Minhas filhas lá comigo e eu grávida do Lucas. Comecei a conhecer o pessoal do acampamento e entrei pra coordenação do setor. Eles foram minha família pra tudo. Até hoje! Enfrentei com eles sol, chuva, polícia, spray de pimenta. E grávida!

Léa, ao contar sua história de envolvimento como o MTST, muda de postura corporal. Se antes falava com certa timidez, cabeça baixa, muitas vezes chorando ao lembrar-se das dificuldades e humilhaçóes vivenciadas, ao relatar sua experiência no acampamento, deixa transparecer alegria e empolgação. O engajamento lhe possibilitou, pela primeira vez, vivenciar laços de afeto familiar, aprender sobre seus direitos como cidadã e trabalhadora, bem como a negar o "destino" que parecia ter sido traçado à sua revelia: "quando minha mãe morreu, todo mundo dizia que meu irmão ia ser vagabundo e eu prostituta".

Léa morou na ocupação durante seis meses; dada sua precária situação, foi priorizada no recebimento do auxílio aluguel. Pela primeira vez em muito tempo, ela moraria em uma casa digna e sem depender de "favores" de outras pessoas. No entanto, não havia móveis, nem roupas, sequer havia comida em alguns dias. Apesar disso, a possibilidade de ter endereço fixo, uma habitaçáo digna e o apoio dos companheiros do MTST, em diferentes sentidos, possibilitou uma guinada na vida dessa mulher, que conseguiu um emprego formal, como cozinheira, garantindo o sustento da família ao longo da luta pelo seu apartamento. 
Tinha um bom salário, ganhava $\mathrm{R} \$ 1.200,00$. Fui comprando minhas coisinhas, os móveis. Faltando um mês pra receber as chaves [do apartamento no João Cândido], fui despedida. A empresa faliu. Perdi de um lado, mas ganhei de outro. No dia 20 de dezembro de 2014, recebi a chave do meu apartamento! Com o seguro desemprego, fui pagando as primeiras prestaçóes. Agora, arrumei um trabalho de cozinheira numa casa no Morumbi. Não deixo faltar nada pros meus filhos. Se eu morrer hoje, morro feliz, porque meus filhos têm onde dormir.

Durante os dez anos em que esteve engajada na luta por moradia no MTST, Léa participou ativamente como coordenadora de diferentes comissóes, inclusive ajudando na organização de novos acampamentos. Seu protagonismo como militante possibilitou até mesmo que viajasse para conhecer ocupaçóes em outras cidades. Apesar de ter conquistado sua casa, Léa ainda participa de assembleias, marchas, manifestaçóes e organizaçóes de novos acampamentos.

Eu fico com vontade de ir pra luta. Eles são minha família. Não acho justo virar as costas (...). Às vezes, arrumo briga dentro do ônibus, porque tem gente, quando tem marcha, tem luta do movimento, que fala: "esse monte de desocupado, de vagabundos, ficam fechando o trânsito, a gente cansado!" Aí já cheguei brigar mesmo de falar assim: "monte de vagabundo não, porque eu sou uma delas, do meio deles, sou trabalhadora também e tô aqui no meio de vocês, que tá vindo do serviço, mas hoje eu agradeço a esse monte de vagabundo que vocês falam aí, por isso que eu tenho um teto hoje! Porque se eu dependesse do governo ou de qualquer coisa, nem com o salário que a gente ganha, sendo humilhado, a gente não consegue uma casa! E eles num tão aí só por casa, lutam por vocês que tão aqui em pé dentro do ônibus, vocês que táo no posto de saúde procurando uma consulta e não tem e por uma escola melhor pros seus filhos! E vocês nem imaginam, né, que esse benefício não é só pra eles que tá lá, é pra vocês que tão aqui também?

Léa mora com dois de seus filhos e sua filha de 16 anos já participa das ações do MTST. De posse de sua casa, faz planos para o futuro: "quero voltar a estudar, posso voltar um dia. Se consegui tudo isso, por que náo vou conseguir estudar. Vida mais amarga que a minha não teve, mas eu consegui adoçar".

\section{O engajamento em contextos de alta vulnerabilidade social e econômica: considerações finais}

De acordo com Gaxie (1978), a politização ocorre de maneira desigual entre os cidadãos, em função da posse de diferentes níveis de competência polí- 
tica ${ }^{7}$, que variam segundo sua classe social, nível de instrução e capital cultural. Não resta dúvida de que essas variáveis influenciam os processos de politização, no entanto, é preciso tomar grande cuidado na análise do universo das classes populares para não estigmatizá-las nem romantizá-las (BOURDIEU, 1983; GAXIE, 1978). Em uma leitura rápida, as entrevistas, observaçóes e conversas informais com os moradores do condomínio poderiam indicar que a politização, nesse grupo, é pouco consistente e eivada de contradiçóes. Além disso, muitos dos princípios norteadores do MTST, apesar do longo período de luta dessas famílias, não parecem ter sido incorporados às suas práticas e discursos, o que fica evidente nas dificuldades de resoluçáo de diferentes problemas no condomínio, inclusive de inadimplência. No entanto, não é incomum que estudos de outros grupos políticos, com origem social diversa, também apontem contradiçóes e inconsistências: a aderência "total" a um dado projeto político exige configuraçóes muito específicas, assim como ações deliberadas de socialização com orientações ideológicas bastante precisas (PUDAL, 1989; LECLERQ, 2005; CANÊDO, 1991; 2002; MUXEL, 1986; MUXEL \& PERCHERON, 1988).

A análise mais detalhada dos dados, entretanto, aponta que todos os depoentes operam em seu discurso e modo de vida uma refinada "negociação" e "acomodação", de um lado, entre valores familiares e religiosos de defesa da propriedade privada e valorização do esforço individual e, de outro, os princípios socialistas defendidos pelo MTST (SARTI, 2003; BOULLOS, 2012). O que resulta em um "mosaico" ético e político de percepção e avaliação do mundo que distingue, por exemplo, a aquisição de bens por meio de ações ligadas à criminalidade e a conquista, para fins coletivos e populares, de bens, cuja propriedade seria ilegítima e imoral, como no caso dos terrenos irregulares. Assim, os valores adquiridos na família persistem ao longo do tempo, mas são resignificados na trajetória dos entrevistados, sobretudo diante dos desafios de uma vida de trabalho e honestidade sem perspectiva concreta de ascensão social. E, nesse caso, a vivência das condiçóes indignas de moradia aparece como uma barreira absolutamente concreta dos limites do que se é possível conquistar somente pelo esforço individual, em outras palavras, trata-se da "falência" concreta de todo e qualquer argumento meritocrático. O encontro com o MTST confere sentidos a essa constatação, que se desdobra na "luta" e pelo "amor à luta".

A socialização não se resume à simples aceitação de atitudes e de comportamentos 'prêts à porter'; ela é um processo de construção da identidade dos sujeitos e isso resulta da incorporação, da apropriação pelo sujeito de valores, de normas e saberes de seu grupo, que conduz, notadamente, à reorganização das referências do passado. Em uma espécie de 'inversão" dos papéis entre socialização e tradição, a socialização torna-se, então, um instrumento de recriação da tradição (PERCHERON, 1987, p. 45). 
A religiáo, por exemplo, é uma das dimensóes que exigem contínua adaptação e acomodação valorativa. $\mathrm{O}$ condomínio conta com significativa presença de evangélicos entre seus moradores, o que faz todo sentido quando pensamos nos dados que apontam o Brasil como o país com maior número de evangélicos no mundo, sobretudo nas camadas mais pobres da população (MARIANO, 2004; 2009; BOHN, 2004). Os entrevistados frequentam um amplo leque de igrejas evangélicas, das mais conservadoras às mais progressistas. $\mathrm{E}$, nesse sentido, vale a pena destacar que Ana, por exemplo, iniciou sua luta por moradia antes de conhecer o MTST, exatamente em um movimento evangélico, denominado "Povo em açáo", que atuava na regiáo do Capáo Redondo, periferia da Zona Sul de São Paulo, e tinha como princípio a ideia de que "Deus age através da união do povo", portanto, radicalmente oposto às ideias professadas pela teologia da prosperidade ${ }^{8}$.

Para concluir, retomando a proposição de Gaxie (1978; 2002), nossos dados parecem confirmar que há determinados aspectos da politização que são, de fato, condicionados pela classe social e, sobretudo, pela posse de capitais culturais e escolares, redundando em diferentes níveis de compreensão e elaboração a respeito da própria atuação política, o que, nesse caso se expressa na dificuldade de se declarar como alguém que "gosta de política", em função do sentimento de incompetência e ilegitimidade social, e nos limites para assumir o protagonismo do movimento, que é atribuído integralmente às suas lideranças. No entanto, parece haver pontos em comum nos processos de politização, independentemente da posição social dos militantes, como a sensação de ter vivido um "segundo nascimento", de encontrar uma nova família e passar a ter outros sentidos para sua existência, que extrapolam as conquistas individuais (GAXIE, 1978; PENNETIER \& PUDAL, 1996; BOURDIEU, 1977; YON, 2005; TOMIZAKI, 2009; SUÁREZ, 2004).

Finalmente, vale sublinhar que a compreensão refinada dos processos de socialização, socialização política e politização, bem como do peso da escolarização sobre as possibilidades e limites da organizaçáo coletiva no seio das classes populares, abre perspectivas importantes para se compreender, de um lado, a persistência das brutais desigualdades em nosso país e, de outro, a potencialidade política dessa camada social, em geral pouco considerada na discussóes pautadas na teoria clássica de classes sociais.

\section{Notas}

1. Os trabalhos de Lima (2004), Oliveira (2010) e Goulart (2011) analisam a gênese histórica do movimento.

2. A bolsa aluguel refere-se a um benefício concedido por algumas prefeituras, como Sáo Paulo e Taboão da Serra, destinado às parcelas mais pobres da população que perderam suas casas em decor- 
rência de desastres naturais. Entretanto, o MTST, por meio de diversas mobilizaçóes, incluindo a greve de fome de sete militantes, em 2005, conseguiu que esse benefício pudesse ser estendido às famílias ligadas ao movimento, especialmente àquelas em situação de maior vulnerabilidade.

3. A política será entendida nesse artigo como (i) a esfera ligada diretamente à administração do Estado; (ii) a esfera formada por aqueles que, de forma organizada, remetem-se ao poder institucionalizado, seja para apoiá-lo ou para questionar sua atuação e lutar pelos seus interesses; (iii) as manifestações contestatórias, artísticas e culturais que não necessariamente são organizadas, não se dirigem ao Estado, nem possuem uma pauta de reivindicaçôes (SIMON, 1989; AÏT-AOUDIA et al., 2011).

4. No Brasil, os estudos sobre socialização política têm forte interlocução com a literatura norte-americana e se desenvolveram em diálogo com os estudos sobre transmissão e assimilação de diferentes culturas políticas (BARQUERO, 2010; SCHMIDT, 2000; FUKS, 2011; 2014; ROBALLO, 2011; ARAÚJO, 2009).

5. Ana sofre de miastenia crônica, uma doença neurológica que provoca fadiga muscular, especialmente nos braços e pernas, visão dupla e dificuldades para falar.

6. Guilherme Boullos é a mais conhecida liderança do MTST.

7. As competências políticas podem ser classificadas em três tipos: i) a competência técnica, que diz respeito ao conhecimento sobre o funcionamento do sistema político; ii) a competência strictu sensu, que versa sobre a capacidade do indivíduo se situar em um eixo político ideológico (direita ou esquerda); e iii) a competência social, que considera o interesse dos indivíduos pela política (MUXEL \& PERCHERON, 1985; PERCHERON, 1993).

8. De acordo com o IBGE (2010), 22,2\% da população brasileira é evangélica e $67,7 \%$ tem renda até um salário mínimo, característica que, segundo Bohn (2004), não pode ser considerada como uma exclusividade das religióes evangélicas, visto que católicos também em sua maioria $(55,8 \%)$ têm a mesma faixa de renda. O Pentecostalismo brasileiro é dividido em três grupos, segundo critérios históricos e teológicos: (i) Pentecostalismo clássico ou histórico; (ii) Sem "denominação consensual", teve início na década de 1950 com a chegada de missionários norte-americanos e tem por principal base teológica a pregação da cura divina; (iii) Neopentecostalismo, data dos anos 1970, responsável pela difusão da chamada teologia da prosperidade, que enfatiza o "direito" à prosperidade para o cristão, que deve viver bem, ser saudável e vitorioso, inclusive financeiramente. No Brasil, tanto pentecostalistas quanto neopentecostalistas são considerados evangélicos, em todas as vertentes são comuns as interdiçóes do uso de álcool, cigarro e drogas, o sexo extraconjugal e a homossexualidade. Além da expansão numérica de fiéis, esse movimento religioso tem estendido sua participação também nos campos midiático, político partidário, assistencial, editorial e de produtos religiosos. Trata-se de um fenômeno que chama a atençáo nos debates atuais sobre a sociedade brasileira. Vale destacar que, segundo alguns autores, nem todas as igrejas evangélicas podem ser consideradas fundamentalistas e conservadoras (IBGE, 2010; BOHN, 2004; MARIANO, 2004; 2009; 2011; PIERUCCI, 1989; PIERUCCI; PRANDI, 1995). 


\section{Referências}

AÏT-AOUDIA M.; MOUNIA, B.-C.; JEAN-GABRIEL, C. Indicateurs et vecteurs de la politisation des individus: les vertus heuristiques du croisement des regards. Critique Internationale, n. 50, p. 9-20, 2011.

ARAÚJO, A.L. A importância dos agentes de socialização política na participação política dos jovens. In: SEMINÁRIO NACIONAL SOCIOLOGIA \& POLÍTICA UFPR, 1., 2009. Grupo de Trabalho 8: Cultura e Socialibilidades. Sociologia e Politica. Paraná: UFPR, 2009.

BARGEL, L. Socialisation politique. In: FILLIEULE, O.; MATHIEU, L.; PÉCHU, C. (Orgs.). Dictionnaire des mouvements sociaux. Paris: Presses de Sciences Po, 2009. p. 510-517.

BARQUERO, M. Cultura política e processo eleitoral no Brasil: o que há de novo? Em Debate, Belo Horizonte, v. 2, n. 7, p. 6-10, jul. 2010.

BERGER, P.; BERGER, B. Socialização: como ser um membro da sociedade. In: FORACCI, M; SOUZA MARTINS, J. (Orgs.). Sociologia e sociedade: leituras de introdução à sociologia. São Paulo/Rio de Janeiro: Livros Técnicos e Científicos, 1975. p. 200-214.

BERGER, P.; LUCKMANN, T. A sociedade como realidade subjetiva. In: BERGER, P.; LUCKMANN, T. A construção social da realidade: tratado de sociologia do conhecimento. Petrópolis: Vozes, 2004.

BERTONCELO, E.R.E. Classes sociais no Brasil. Plural, Sáo Paulo, v. 21, n. 2, p. 8-19, dez. 2014. Disponível em: shttp://www.revistas.usp.br/plural/article/view/97181/96234>. Acesso em: 19 maio 2016.

BOHN, S.R. Evangélicos no Brasil. Perfil socioeconômico, afinidades ideológicas e determinantes do comportamento eleitoral. Opinião Pública, Campinas, v. 10, n. 2, p. 288-338, out. 2004.

BOULLOS, G. Por que ocupamos? Uma introdução à luta dos sem-teto. São Paulo: Scortecci, 2012.

BOURDIEU, P. O senso prático. Petrópolis: Vozes, 2009.

. Questions de politique. Actes de la Recherche en Sciences Sociales, n. 16, set. 1977. . Vous avez dit "populaire"? Actes de la Recherche en Sciences Sociales, v. 46, mar. 1983. ; WACQUANT, L. Réponses: pour une anthropologie réflexive. Paris: Seuil, 1992.

CAETANO, P.J.C. Individuação e reconhecimento: processos de socializaçäo política na incerteza dos itinerários escolares. 2013. Tese (doutorado). Faculdade de Ciências Sociais e Humanas, Universidade Nova de Lisboa.

CANÊDO, L. Estratégias familiares na construção social de uma qualificação política. Educação e Sociedade, ano XII, ago. 1991.

Heritage en politique, ou comment acquerir les dispositions et competences necessaires aux fonctios de representations politique (1948-1964). Cahiers du Brésil Contemporain, Paris, n. 47/48, 2002. 
COLLOVALD, A.; SAWICKI, F. Le populaire et le politique. Quelques pistes de recherche en guise d'intrduction. Politix, v. 4, n. 13, p. 7-20, 1991.

DARMON, M. La socialisation: domaines et approches. 2. ed. Paris: Armand Colin, 2010.

DUBAR, C. A socialização: construção das identidades sociais e profissionais. São Paulo: Martins Fontes, 2005.

DUCHESNE, S. HAEGEL, F. La politisation des discussions au croisement des logiques de spécialisation et de conflictualisation. Revue Francaise de Science Politique, v. 54, n. 6, p. 877-909, 2004.

FILLIEULE, O.; PUDAL, B. Sociologie du militantisme: problématisations et déplacement des méthodes d'enquête. In: ; AGRIKOLIANSKY, E.; SOMMIER, I. Penser les mouvements sociaux: conflits sociaux et contestations dans les societés contemporaines. Paris: La Découverte, 2010.

FUKS, M. Efeitos diretos, indiretos e tardios: trajetórias da transmissáo intergeracional da participação política. Lua Nova, São Paulo, v. 83, p. 145-178, 2011.

. Explicando os efeitos de programas de socialização política: a experiência do Parlamento Jovem no Brasil. Opiniáo Pública, v. 20, n. 3, p. 425-449, dez. 2014.

GAXIE, D. Appréhensions du politique et mobilisations des expériences sociales. Revue Française de Science Politique, v. 52, n. 2, p. 145-178, 2002.

. Le cens caché: inégalités culturelles et ségrégation politique. Paris: Le Seuil, 1978.

GOULART, D.C. O anticapitalismo do movimento dos trabalhadores sem-teto MTST. 2011. 276 f. Tese (Doutorado). Universidade Estadual Paulista Júlio de Mesquita Filho, Marília. GUIMARÃES, A.S.A. Classes sociais. In: MICELI, S. (Org.). O que ler na Ciência Social brasileira. São Paulo: Sumaré, 1999.

IHL, O. Socialisation et événements politiques. Revue Française de Science Politique, v. 52, n. 2-3, p. 125-144, 2002.

INSTITUTO BRASILEIRO DE GEOGRAFIA E ESTATÍSTICA - IBGE. Censo demográfico 2010: primeiros resultados. Rio de Janeiro, 2010.

LAGROYE, J. La politisation. Paris: Belin, 2003.

LAGROYE, J.; BASTIEN, F.; SAWICKI, F. Sociologie politique. Paris: Presses de Sciences Po et DAlloz, 2006.

LECLERCQ, C.P.J. Les incidences biographiques de l'engagement. Socialisations militantes et mobilité sociale. Sociétés contemporaines, n. 84, p. 5-23, 2011.

. Raisons de sortir. Le désengagement des militants du Parti communiste français. In: FILLIEULE, O. (Org.). Le désengagement militant. Paris: Belin, 2005.

LIMA, S.L.R. Metamorfoses na luta por habitação: o Movimento dos Trabalhadores Sem Teto (MTST). 2004. Tese (Doutorado em Planejamento Urbano e Regional). Universidade Federal do Rio de Janeiro, Rio de Janeiro. 
MARIANO, R. Expansão pentecostal no Brasil: o caso da Igreja Universal. Estudos Avançados, São Paulo, v. 18, n. 52, p. 121-138, 2004.

- Pentecostais e política no Brasil: do apolitismo ao ativismo corporativista. In: SANTOS, H. (Org.). Debates pertinentes: para entender a sociedade contemporânea. [Dados eletrônicos]. Porto Alegre: EDIPUCRS, 2009. v. 1.

Sociologia do crescimento pentecostal no Brasil: um balanço. Perspectiva Teológica, Belo Horizonte, ano 43, n. 119, p. 11-36, jan./abr. 2011.

MOVIMENTO DOS TRABALHADORES SEM TETO - MTST. Cartilha de princípios e linhas organizativas. 2013. Disponível em: <http://issuu.com/mtsemteto/docs/mtst_ cartilha/10?e=9413747/4976282>. Acesso em: 30 jul. 2016.

MUXEL, A. Chronique familiale de deux héritages politiques et religieux. Cahiers internationaux de sociologie, v. 81, p. 255-280, jul./dez. 1986.

. Individu et mémoire familiale. Paris: Nathan Essais \& Recherches, 1997.

. L'expérience politique des jeunes. Paris: Presses des Scieces Politiques, 2001.

MUXEL, A.; PERCHERON, A. Histoires politiques de famille. Premières illustrations. Life Stories/Récits de Vie, Paris, v. 1, 1985.

. Histoires politiques de famille: premières illustrations. Life Stories/Récits de vie, n. 4, p. 59-73, 1988.

OLIVEIRA, N.C. Osmovimentos dos sem-teto da Grande São Paulo (1995-2009). 2010. Dissertação (Mestrado). Instituto de Filosofia e Ciências Humanas, Universidade Estadual de Campinas.

OPPO, A. Socialização política. In: BOBBIO, N.; MATTEUCCI, N.; PASQUINO, G. Dicionário de política. 13. ed. Brasília: Editora da UnB, 2009. v. 2.

PENNETIER, C.; PUDAL, B. Écrire son autobiographie (les autobiographies communiste d'instituitions - 1931-1939). Genèse, n. 1, p. 53-75, v. 23, 1996.

PERCHERON, A. La socialization politique. Paris: Armand Colin, 1993. set. 1987 .

Socialisation et tradition: transmission et invention du politique. Pouvoirs, n. 42,

PIERUCCI, A.F.O. Representantes de Deus em Brasília: a bancada evangélica na constituinte. Ciências Sociais Hoje, São Paulo, n. 11, p. 104-132, 1989.

PIERUCCI, A.F.O.; PRANDI, J. R. Religióes e voto: a eleição presidencial de 1994. Opiniáo Pública, v. 3, n. 1, p. 20-43, jun. 1995.

PUDAL, B. Prendre Parti: pour une sociologie historique du PCF. Paris: Presses de la Fondation Nationale des Sciences Politiques, 1989.

ROBALLO, J.H.M. Cultura política, socialização política e internet: um estudo de caso com os estudantes de ensino médio de Rio Pardo/RS. 2011. Dissertação (Mestrado). Programa de PósGraduação em Ciência Política, Universidade Federal do Rio Grande do Sul, Porto Alegre.

SARTI, C.A. A família como espelho: um estudo sobre a moral dos pobres. Sáo Paulo: Cortez, 2003. 
SAWICKI, F.; SIMÉANT, J. Inventário da sociologia do engajamento militante. Nota crítica sobre algumas tendências recentes dos trabalhos franceses. Sociologias, Porto Alegre, v. 13 , n. 28 , set./dez. 2011.

SCHMIDT, J.P. Juventude e política nos anos 1990: um estudo de socialização política. 2000. Tese (Doutorado). Universidade Federal do Rio Grande do Sul, Porto Alegre.

SCHWARTZ, O. Peut-on parler des classes populaires? 2011. Disponível em: <http://www. laviedesidees.fr/Peut-on-parler-des-classes.html>. Acesso em: 28 jun. 2016.

SIBLOT, Y.; CARTIER, M.; COUTANT, I.; MASCLET, O.; RENAHY, N. Sociologie des classes populaires contemporaines. Paris: Armand Colin, 2015.

SIMON, M. Comportement politique. In: FERRÉOL G. (Org.) Dictionnaire de sociologie. Paris: Armand Colin, 1989.

SOUZA, J. A parte de baixo da sociedade brasileira. Interesse Nacional, v. 14, p. 33-41, 2011. . A "ralé" brasileira: quem é e como vive. Belo Horizonte: Editora da UFMG, 2009. Os batalhadores brasileiros: nova classe média ou nova classe trabalhadora? Belo Horizonte: Editora da UFMG, 2012.

SUÁREZ, H.J. Une mystique de la politique - sur l'engagement de prêtres-ouvriers dans lsa guérilla révolutionnaire em Bolivie. Actes de la Recherche en Sciences Sociales, n. 155, 2004.

TOMIZAKI, K. Da militância ao estudo do militantismo: a trajetória de um politólogo. Entrevista com Bernard Pudal. Pro-Posiçôes, Campinas, v. 20, n. 2, p. 129-138, 2009.

. Deux générations de syndicalistes au Brésil: pratiques quotidiennes et formation politique. Actes de la Recherche en Sciences Sociales, v. 196-197, p. 102-113, 2013.

Transmitir e herdar: o estudo dos fenômenos educativos em uma perspectiva intergeracional. Educação e Sociedade, Campinas, v. 31, n. 111, abr./jun. 2010.

YON, K. Modes de sociabilité et entretien de l'habitus militant. Militer en bandes à l'AJSOCI dans les années 1970. Politix, v. 70, p. 137-167, 2005.

Recebido em 11 de julho de 2016.

Aprovado em 19 de outubro de 2016. 